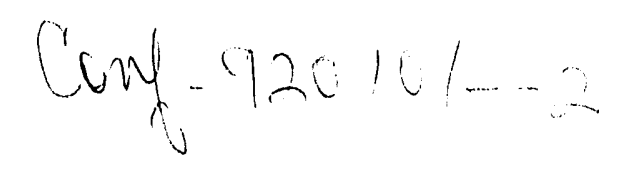

PNL-SA- -20080

DE92 007523

\title{
EFFECTIVE MAINTENANCE PRACTICES TO MANAGE SYSTEM AGING
}

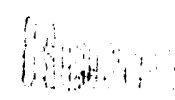

FI:

\author{
A. Chockie \\ K. Bjorkelo
}

January 1992

\author{
Presented at the \\ 1992 Annual Reliability \& \\ Maintainability Symposium \\ January 20-23, 1992 \\ Las Vegas, Nevada
}

\author{
Work supported by \\ the U.S. Department of Energy \\ under Contract DE-AC06-76RLO 1830
}

\author{
Pacific Northwest Laboratory \\ Richland, Washington 99352
}

\section{DISCLAIMER}

\begin{abstract}
This report was prepared as an account of work sponsored by an agency of the United States Government. Neither the United States Government nor any agency thereof, nor any of their employees, makes any warranty, express or implied, or assumes any legal liability or responsibility for the accuracy, completeness, or usefulness of any information, apparatus, product, or process disclosed, or represents that its use would not infringe privately owned rights. Reference herein to any specific commercial product, process, or service by trade name, trademark, manufacturer, or otherwise does not necessarily constitute or imply its endorsement, recommendation, or favoring by the United States Government or any agency thereof. The views and opinions of authors expressed herein do not necessarily state or reflect those of the United States Government or any agency thereof.
\end{abstract}




\title{
Effective Maintenance Practices to Manage System Aging
}

\author{
Alan Chockie $\square$ Battelle $\square$ Seattle \\ Kenneth Bjorkelo $\square$ Battelle $\square$ Seattle
}

Key Words: Maintenance Management, Operating Life, Nuclear Power Plant, Aircraft Maintenance, Submarine Maintenance.

\section{SUMMARY \& CONCLUSIONS}

For a variety of economic and technical reasons, there has been a growing concern with the aging of complex systems and components and the role that maintenance can play in reducing this degradation. A study for the Nuclear Regulatory Commission was recently undertaken to identify effective maintenance practices that could be adapted by the nuclear industry in the United States to assist in managing the aging degradation of plant systems and components.

Four organizations were examined to assess the influence that their maintenance programs have on their ability to address the systems and component aging degradation issues.

An effective maintenance program was found to be essential to the management of system and component aging. The four key elements of an effective maintenance program that are important to an aging management program were identified. These are:

- the selection of critical systems and components

- the development of an understanding of aging through the collection and analysis of equipment performance information

- the development of appropriate preventive and predictive maintenance tasks to manage equipment and system aging degradation

- the use of feedback mechanisms to continuously improve the management of aging systems and components

These elements were found to be common to all four organizations. In examining how the four organizations have structured their maintenance programs to include these key elements provides valuable lessons not only for the nuclear power industry, but also for any industrial organization that is concerned with the management of system and component aging degradation.

\section{INTRODUCTION}

As systems and components age, the effectiveness of the maintenance program plays an increasingly important role in safe and economic plant operation. The quality of the maintenance program directly impacts the ability of an organization to detect and mitigate the aging degradation of equipment and systems.

One aspect of the Nuclear Regulatory Commission (NRC) Nuclear Power Plant Aging (NPAR) Program is to assist in understanding the role of maintenance practices in developing and implementing effective aging management programs. The NRC contracted with the Department of Energy's Pacific Northwest Laboratory, operated by Battelle Memorial Institute, and its subcontractor, Battelle Human Affairs Research Center to analyze the effectiveness of maintenance activities in four organizations. The objective of the study was to identify effective maintenance practices from these programs that could be adapted by the U.S. nuclear power industry to assist in managing the aging of the nuclear power plants. (The work was performed under the U.S. DOE Contract DE-AC06-76RLO 1830).

Two of the four organizations examined were Department of Defense organizations--the U.S. Air Force B-52 bomber program and the U.S. Navy ballistic submarine program. The other two organizations were the U.S. commercial aviation industry and the Japanese nuclear power industry. These organizations were selected for the study effort based on the recognized effectiveness of their maintenance programs and the importance to their continued operation of properly addressing system and component aging issues.

\section{MAINTENANCE PHILOSOPHIES}

The philosophies governing the operation and maintenance of a plant have an influence on the approach an organization takes to manage plant aging. The operating philosophies of the four organizations differ markedly--particularly between the military and commercial organizations.

The maintenance programs of the military do not have many of the same constraints as do commercial organizations. For example, the continued operation of a B-52 aircraft is based on the strategic requirements imposed by the Strategic Air Command rather than on economics. The strategic requirement specifies that a certain number of aircraft are mission-ready at all times regardless of the cost.

The maintenance program for Navy ballistic submarines is also driven by the requirement to meet an assigned deployment date. The objective of the maintenance plan is to support the operating schedule and assure safe, reliable operations for extended periods between refueling overhauls (Ref. 1). The maintenance program seeks to maintain 100 percent operational capability during the submarine deployment period, and to minimize maintenance costs throughout the submarine's useful life. 
In contrast, both the Japanese nuclear industry and the U.S. commercial aviation industry use equipment designed to operate as long as is economically feasible. Also, these industrial organizations have limited resources available to conduct maintenance activities.

An assessment of the general approach to maintenance management of these four organizations--taking the differences in their maintenance philosophies into account-identified four common elements of effective maintenance that are important to the management of the aging degradation process. The following sections provide an assessment of some of the maintenance program practices that have been developed by these four organizations to address the aging of their systems and components.

\section{CRITICAL SYSTEMS AND COMPONENTS}

To be effective with the limited resources--time, manpower, and/or budgets--available, management maintenance must be able to prioritize which systems and components are critical to continued safe and economic operation. An essential element of the effective management of the maintenance program is the prioritization of the systems that are critical to the continued safe and economic operation.

One approach to the prioritization of systems and components is Reliability Centered Maintenance (RCM). RCM has been used extensively in the commercial aviation and U.S. Air Force. This process involves the systematic evaluation of system and component failure modes for the identification of critical systems and components, and the development of scheduled preventive maintenance tasks.

In developing the scheduled preventive maintenance requirements for the B-52, the Air Force classifies all aircraft systems and components as either critical or noncritical. The severity of the consequence of component failure determines the classification. Critical systems and components are limited to a certain number of flight hours or duty cycles, or unt1l a specified expiration date. A critical item is then removed, inspected, repaired if necessary, and tested. It may then be reinstalled or placed in spares. Non-critical items remain in service until failure. Normally, when there is a redundancy, the system or component will be classified as non-critical.

During the design stage of a commercial aircraft, the aircraft manufacturers and representatives from the airlines utilize the RCM methodology to develop the initial scheduled preventive maintenance program for the new

plane. The four principal steps in this process are (Ref. 2):

- the identification of critical items that require preventive maintenance

- the identification of the functional failure associated with each component

- the creation of a logic tree to determine applicable maintenance tasks
- the review of the aircraft structure to establish an inspection program

The identification of critical maintenance items requires a detailed physical and functional description of each component specifying all of the functions which it performs.

The functional significance of the critical components on system performance is then assessed in the second step of the RCM process. A failure modes and effects analysis process is used to assist in identifying the dominant causes and failure consequences.

The creation of a logic tree incorporates information from the previous steps to identify applicable and effective maintenance tasks for the component. This process addresses potential multiple failures that could affect safety. In the fourth step, an aircraft structure review is performed. This review covers the critical elements of the primary structure which would have a major impact on structural integrity in the event of a failure. Each element is reviewed to determine its expected fatigue life, crack propagation rate, and corrosion susceptibility. These factors are considered in the development of the inspection program.

In this manner, systems and components which are critical to the continued safe operation of both military and commercial aircraft are selected. Based upon the safety significance of these systems and components, maintenance tasks which are both applicable and effective in mitigating aging are selected for the scheduled preventive maintenance program.

\section{COLLECTION AND ANALYSIS OF PERFORMANCE DATA}

An important aspect of efforts to understand the aging of systems and components is the availability, completeness, and accuracy of equipment operational performance data. Performance data collected during monitoring activities provide the basis to identify maintenance problems, analyze possible causes, and implement corrective actions. It also provides the organization with the information needed to understand the effects of aging on critical systems and components.

For both the Air Force and the commercial aviation industry, the use of RCM requires extensive collection, organization, and evaluation of equipment performance data. Performance indicators used by the Air Force include the usage rates of spare parts, changes in levels of corrective maintenance, and operational readiness ratings. Also, the Air Force has developed a maintenance data collection system to track the maintenance history of B-52 components and systems (Ref. 3).

The Air Force relies mainly on the results of Aircraft Condition Inspections (ACI) to evaluate the effectiveness of its maintenance activities. This is an in-depth inspection 
performed to provide a basis for establishing inspection tasks and developing future inspection schedules. Each year the Air Force selects ten aircraft out of its B-52 fleet for an ACI. The results of the ACIs are systematically reviewed to determine the degree of inspection and overhaul to be performed during routinely scheduled maintenance periods. If a failure is found during an $\mathrm{ACI}$ inspection, thirteen additional aircraft from the B-52 fleet are inspected. If a repeat is found during that inspection, a maintenance task designed to correct the problem is considered as an addition to normally scheduled maintenance work.

The commercial aviation industry also has an extensive system for assessing the effectiveness of its maintenance program. Prior to operation, the initial scheduled maintenance program developed for each aircraft must receive Federal Aviation Administration (FAA) approval. Any changes to the preventive maintenance tasks or frequency must also receive FAA approval based on engineering analysis of operating experience. Airlines therefore maintain a set of performance records for each aircraft in service, and adjust their maintenance activities as a result of the records. Performance records typically include the following information:

- engine shutdown and removal data

- component removals and verified failures

- system level delays and cancellations

- chronic aircraft systems

- engine performance data

Monitoring techniques focus on failure rates, agereliability characteristics, and the use of ranking processes to identify areas needing special maintenance attention. The aircraft manufacturer provides the airlines with information concerning modifications to recommended maintenance activities. The airline provides the manufacturer with reliability and maintenance findings on its aircraft.

A similar performance tracking approach is used by the U.S. Navy. The Navy presently identifies aging problems by observing a change in condition over an extended period of time. At each major overhaul, for example, measurements of equipment operating characteristics are made and stored in a computer database and subsequently used to analy'ie the rate of change in condition due to aging, as weil as other factors. This information is used to determine the pnesent condition, the rate of degradation and the potential remaining useful life of the equipment.

To date, the submarine maintenance plan has proven to be effective in managing aging from an operationai standpoint. Originally, the tirne between major overhauls was set at five years. A dernonstration project involving three ballistic submarines was undertaken by the Submarine Maintenance and Monitoring Support Operation (SMMSO) wherein the overhaul period was extended to seven years, and then to nine years, and finally to twelve years. This project successfully demonstrated the concept of an extended maintenance cycle for ballistic submarines.

\section{MAINTENANCE TASKS TO MANAGE AGING}

The development of maintenance tasks to mitigate aging degradation was found to be the third key element of an effective aging management program. These include tasks designed to detect, identify, and correct problems caused by aging mechanisms such as corrosion, wear, and fatigue before the safety or reliability of the plant is adversely affected.

As mentioned above, the commercial aviation industry uses the RCM methodology to determine the specific maintenance tasks required for a given piece of equipment. Maintenance tasks for systems and components are identified based on the safety-significant classification of the equipment, and on its exhibited relationship between age and reliability.

Tests and inspections are performed during scheduled checks. The frequencies of these tests and inspections are based on such factors as the number of flight-hours, the number of flight cycles, and the chronological age of the aircraft.

Like commercial aircraft, the maintenance schedule for a B-52 aircraft consists of a series of phase inspections scheduled at specified intervals. These phase inspections involve routine preventive and corrective maintenance which can be performed at the aircraft's home base. In addition to the phase inspections, major inspections of the B-52 aircraft are conducted at maintenance depots. These Programmed Depot Maintenance (PDM) inspections are performed every four years on each B-52. At the end of the 4-month PDM, the aircraft has been upgraded with the latest available technology. An Analytic Condition Inspection (ACl) is performed concurrently with the PDM. Based on the results of the ACI, the inspection interval for a system or component may be adjusted to change the frequency of inspections and tests.

Ballistic submarines operate on three-month deployment schedules followed by a 30-day refit period at a submarine tender. During the refits, preventive and corrective maintenance is performed, and the submarine is readied for its next deployment. Approximately once every four years, a 60-day restricted availability is performed. This is an extended maintenance period intended to upgrade systems and components.

Over the 30-year life of the submarine, it is scheduled for refueling approximately every twelve years. During the refueling period extensive preventive and corrective maintenance is performed on many of the submarine's structures, systems and components. The refueling overhaul requires 18 to 24 months. As with the airlines and the Air Force, the Navy relies on extensive use of non- 
destructive evaluation techniques to assess the operating condition of many submarine systems and components.

The Japanese have regularly scheduled maintenance and inspection outages in conjunction with plant refueling. The work scheduled for these outages is part of a 10-year inspection plan that is developed and submitted to the Ministry of International Trade and Industry (MITI). MITI, the Japanese regulatory authority for nuclear power plants, also receives annual updates of the 10 -year plans from the nuclear utilities.

The current periodic inspection program in the Japanese nuclear industry governs all operating commercial plants, and occurs approximately every twelve months, requiring the plant to shut down for a three to four-month maintenance period. During the outage, approximately 70 nuclear plant systems and components are disassembled or functionally inspected. The inspections consist of nondestructive tests, overhaul inspections and functional tests designed to determine and alleviate the effects of aging in nuclear plant systems. The tests and inspections are characterized by a wide application of preventive maintenance concepts; valves, pumps and other components are disassembled and checked regardless of whether they have failed in service. Extensive post-maintenance tests are performed before the plant is restarted. MITI collects and analyzes data on equipment data during the periodic outages and uses the results of this data to recommend modifications to maintenance and inspection practices.

\section{CORRECTIVE ACTIONS TO IMPROVE MAINTENANCE EFFECTIVENESS}

Important information on how best to improve the maintenance program to deal with the changing requirements of aging systems is available in performance data gathered during equipment monitoring. The ability of an organization to collect and evaluate equipment performance data is critical to improvement of the maintenance program. Different organizations were found to take different approaches to analyze performance data in order to identify and initiate corrective actions to their existing maintenance programs. The following is a review of approaches taken by the Air Force and the commercial airline industry.

The Air Force convenes a Product Improvement Working Group (PIWG) every three months to review performance, needed improvements and design modifications on the B52. These reviews are based on flight performance data, repair records, and pilot and crew feedback. The purpose of the PIWG is to resolve major maintenance problems, such as directing procedural changes and initiating development programs or authorizing aircraft engineering changes and modifications. This working group is multidisciplinary, representing all parties involved with the aircraft. The Air Force has empowered this group to make recommendations, and generally funds and implements their proposals.

In the commercial aviation industry, time limitations for overhauls and inspections of aircraft systems and components are established as part of an aircraft maintenance program. These limitations continually change as technological advances in airframe, engine, and equipment design occur, and as knowledge expands on preventive maintenance. Airlines can initiate changes in their maintenance inspection schedule through negotiations with the FAA based on specific operating experience data or engineering studies. The manufacturer recommends changes by issuing Service Bulletins to the airlines, and the FAA issues Airworthiness Directives when mandatory changes to maintenance programs are required.

When a problem that has fleet-wide safety implications arises, the manufacturer issues a Service Bulletin. The Service Bulletins focused on areas of aircraft structures which were discovered to experience fatigue and corrosion damage not addressed in the initial maintenance program. These Service Bulletins have since evolved into a formal mandated structural inspection program, and is one of the aviation industry's main programs to address the issues of aging aircraft.

When a condition has heen verified as a safety significant problem, the FAA develops an Airworthiness Directive (AD) to correct unsafe conditions revealed by service experience. The AD is the primary vehicle by which the FAA mandates fleet-wide inspection and repair changes. In general, considerable discussions among the manufacturer, airline and the FAA precede the issuance of an AD. Most $\mathrm{ADs}$ and other design changes are intended to improve the safety, reliability, or maintainability of aircraft.

A new emphasis on structural requirements has resulted from the April 1988 Aloha Airline 737 accident. Based on recommendations of the industry's Airworthiness Assurance Task Force, the FAA has ordered structural modifications to older aircraft, signaling a change maintenance policy. Previously, the FAA had required only perindic inspections to detect structural fatigue and corrosion damage, and called for replacement only when such conditions were found. The new approach of structural modifications prior is the aviation industry's latest effort to combat fatigue and corrosion damage, which are the predominant dangers to aging aircraft.

\section{REFERENCES}

1. J. H. Mason, B. K. Livingston \& E. J. Clarke, "Application of Submarine Extended Operating Cycle Programs to the Enhancement of Commercial Nuclear Power Plant Operation and Maintenance," American Nuclear Society (United States) Trans., 1988 April, vol. 56, pp 52-53. 
2. T. D. Matteson, J. F. McDonald, \& A. M. Smith, Commercial Aviation Experience of Value to the Nuclear Industry, 1984, NP-3364, Los Alamos Technical

Associates, Inc., Los Alamos, New Mexico.

3. R. Summitt, et al., Extending the Lifetime of Operational Systems through Corrosion Tracking and Prediction, 1983, DTIC, AD A133931. 


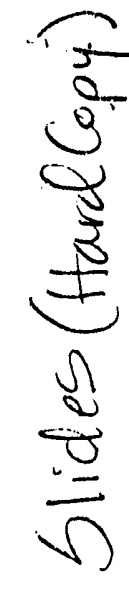

U

0

$\sum \quad \frac{2}{1}$

iv

$\frac{5}{5}$

$F$

2

$\overline{1}$

$\sum$

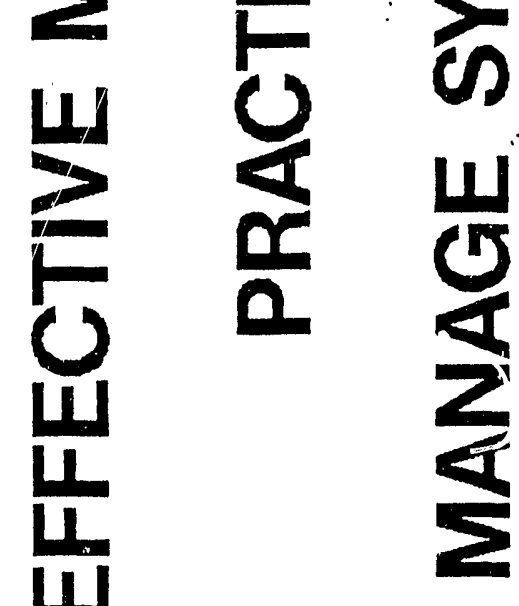

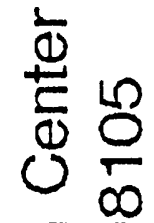

$5 \quad \frac{0}{0} \stackrel{\infty}{0}$

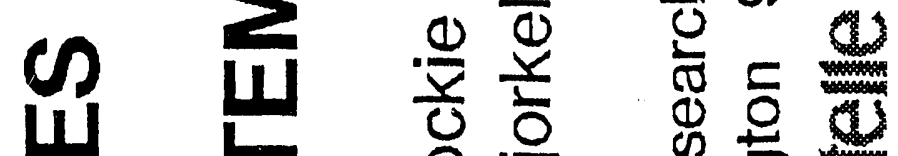

$\cos$

\&

此

F 0

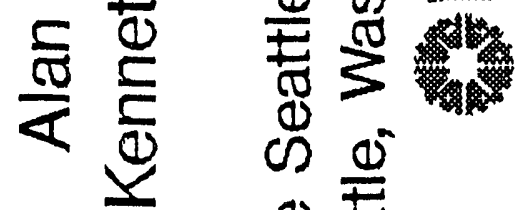

心 $\frac{\Phi}{ \pm}$

$\frac{1}{2}$ 


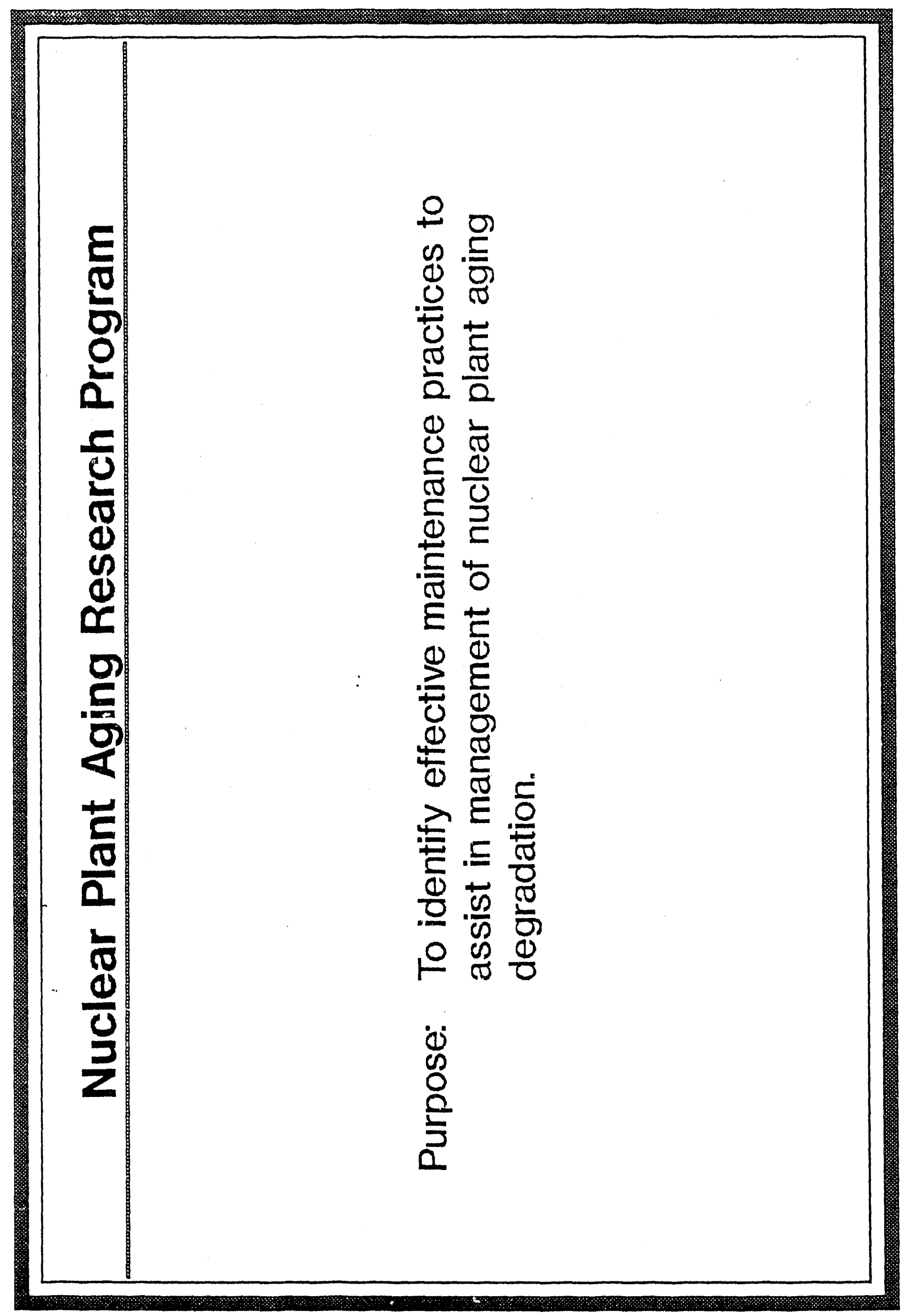




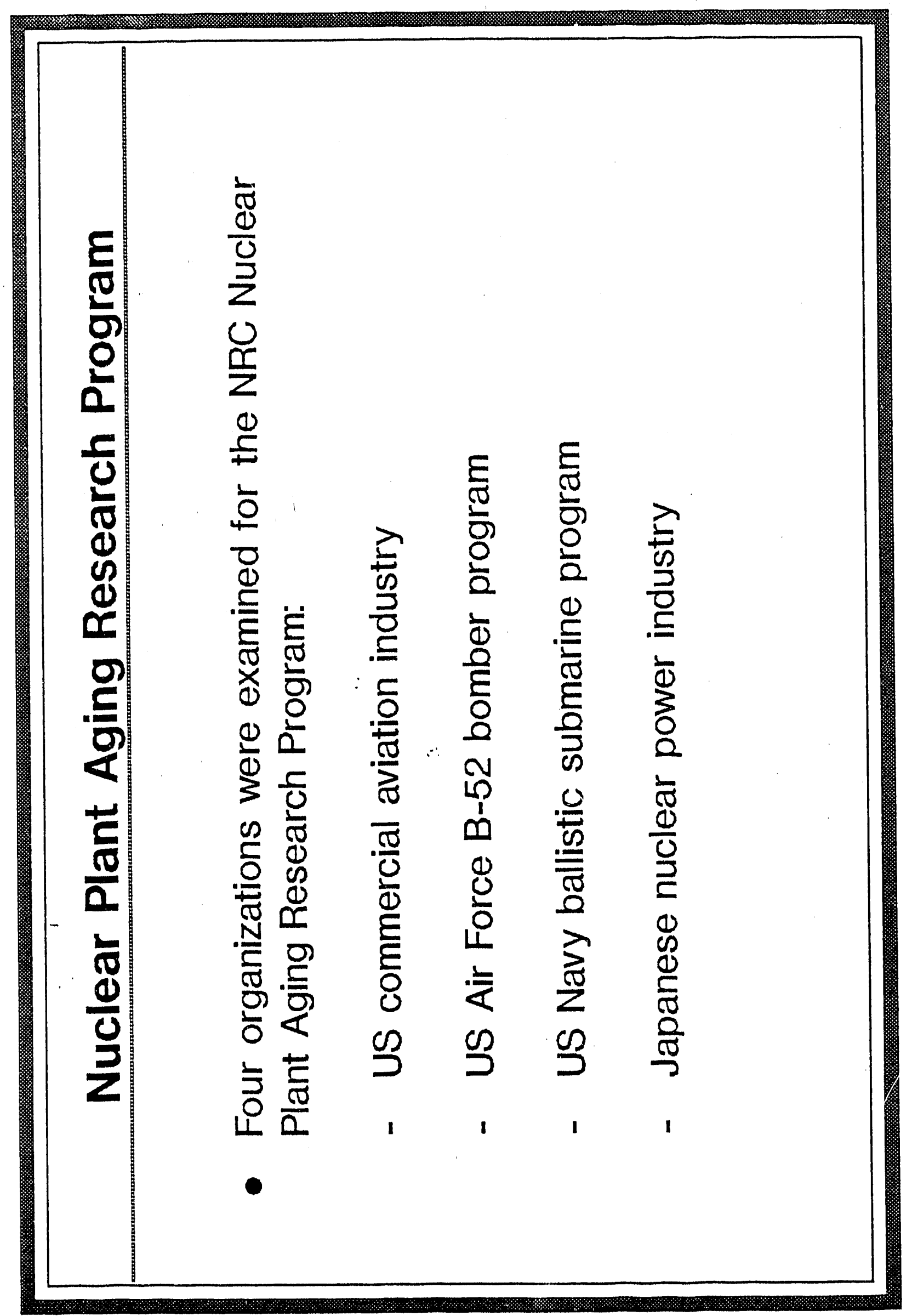




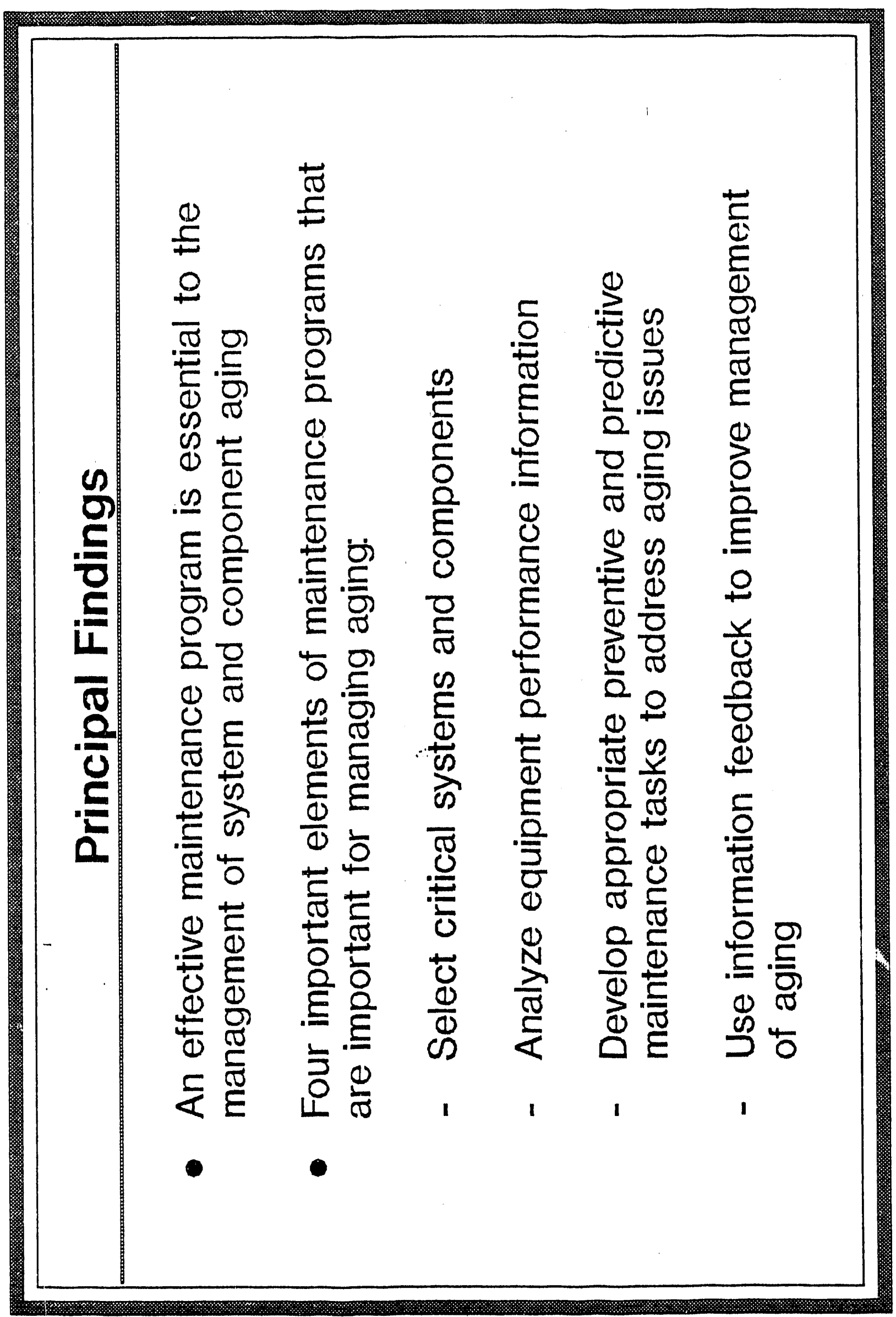




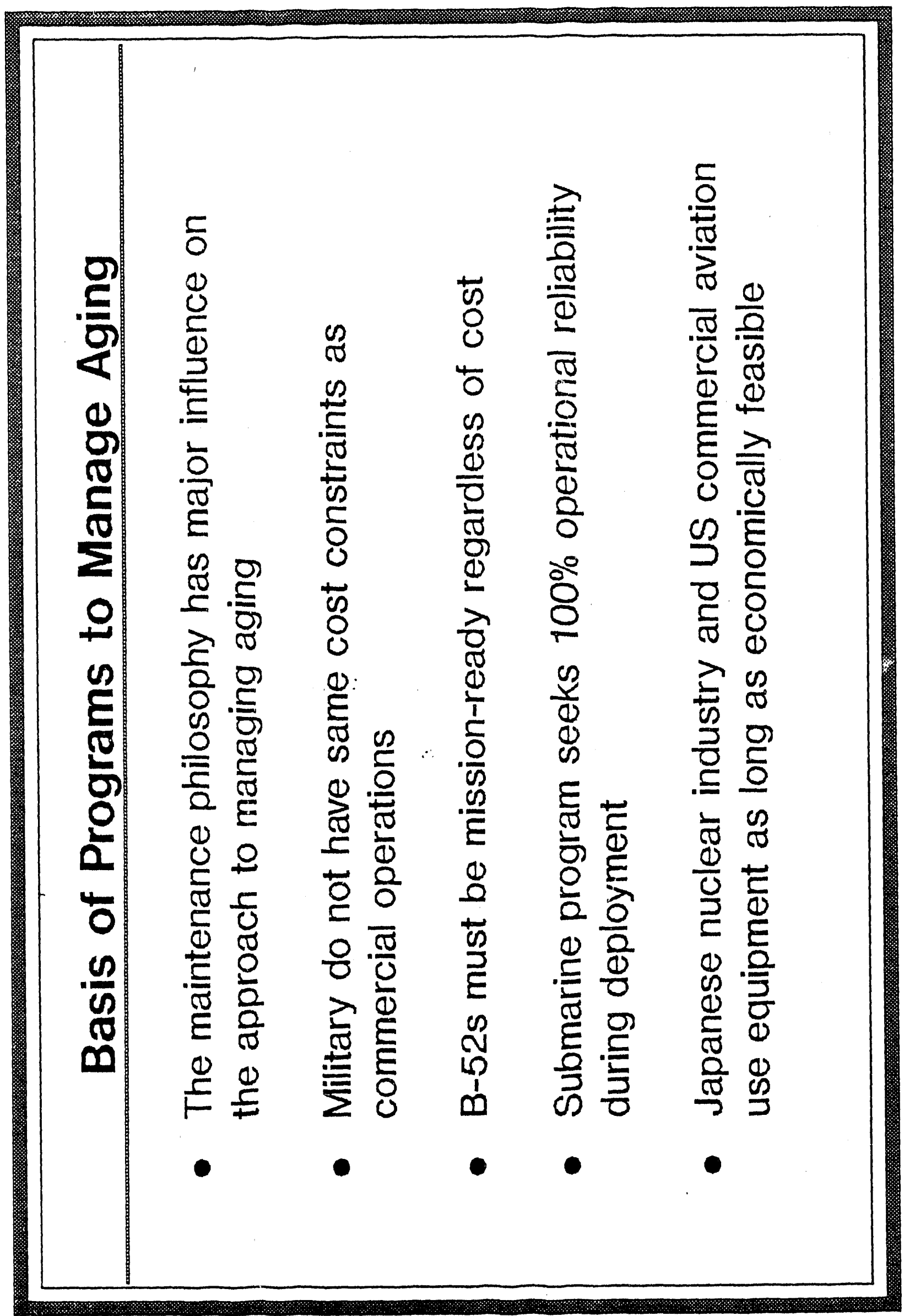




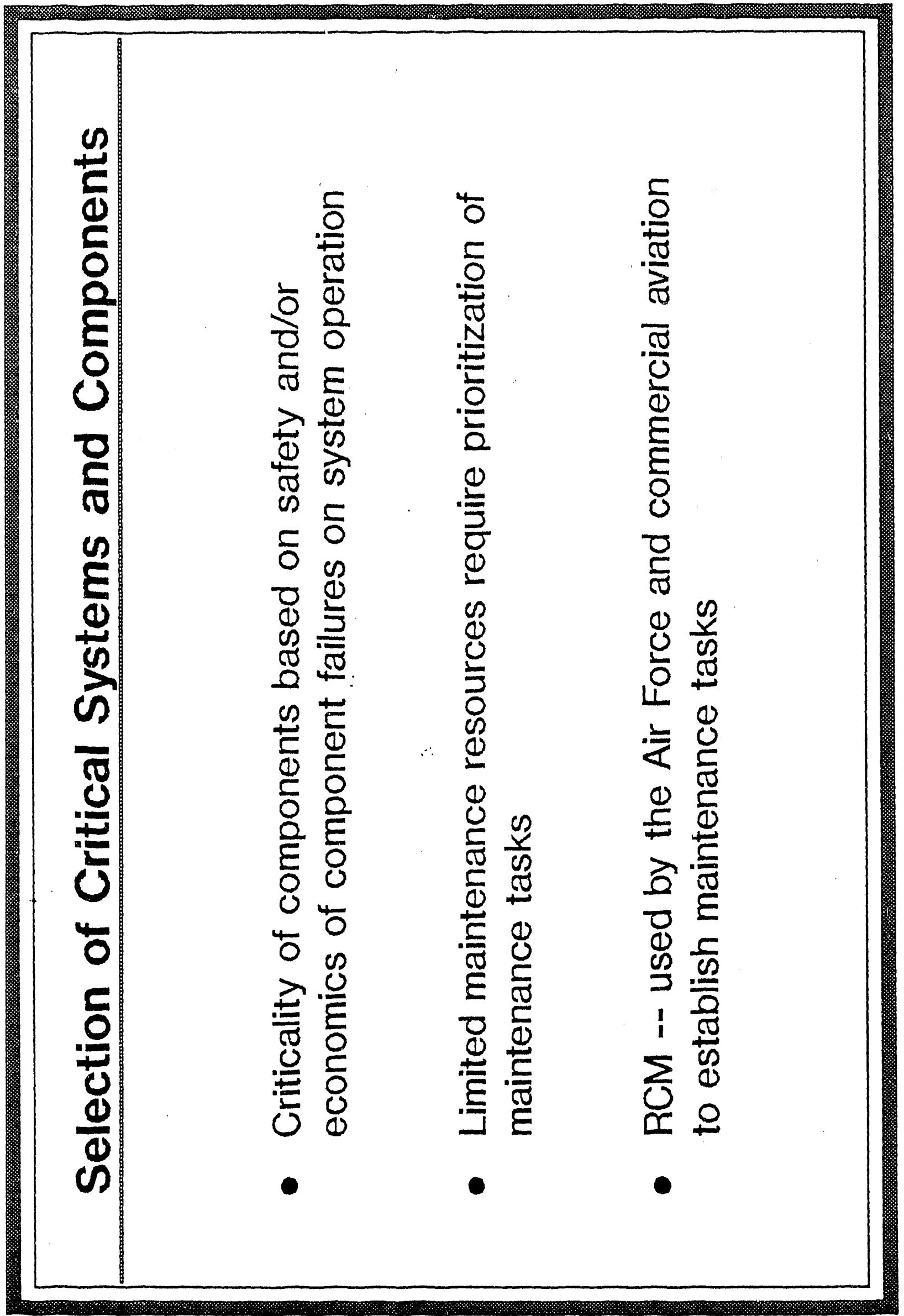




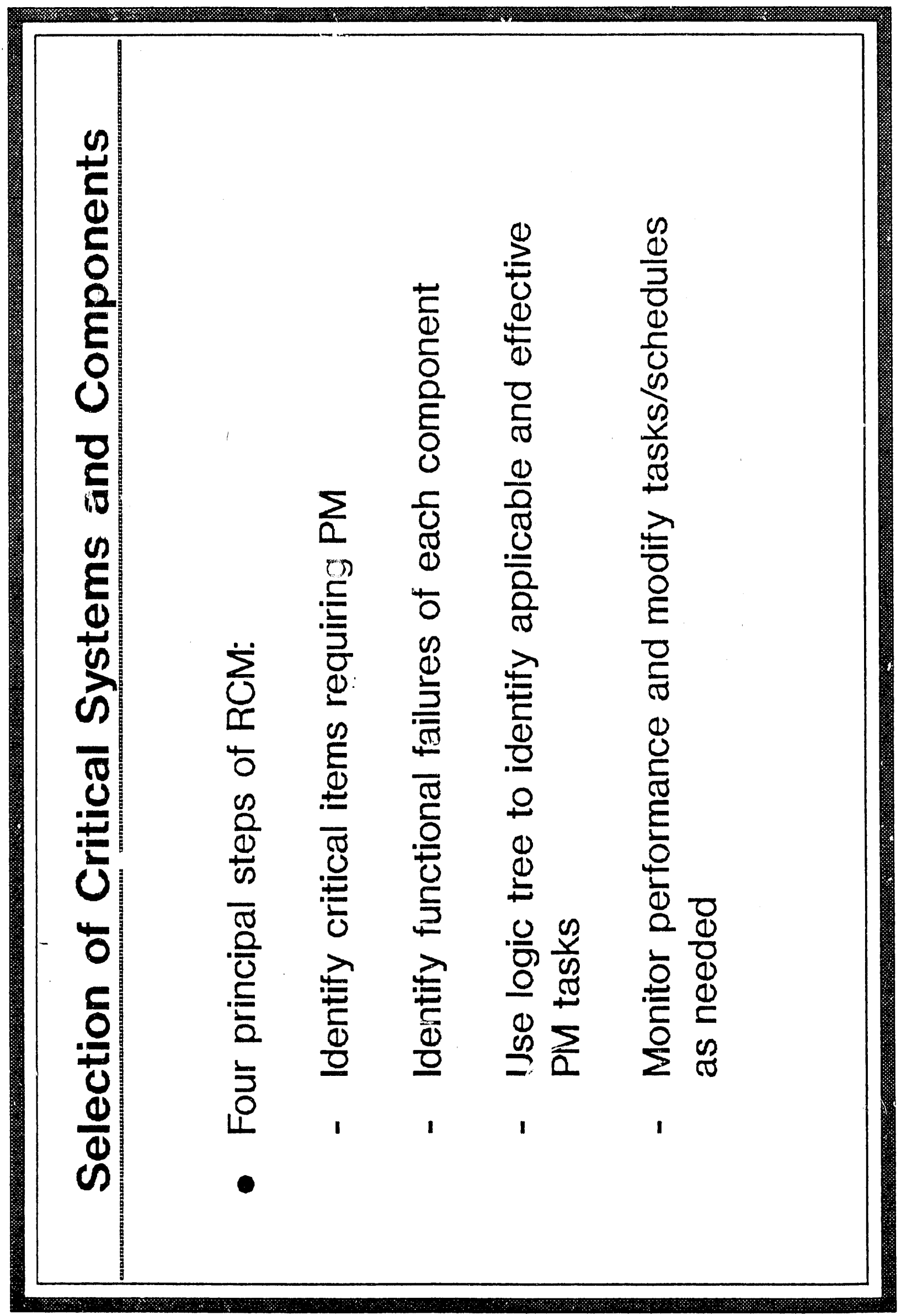




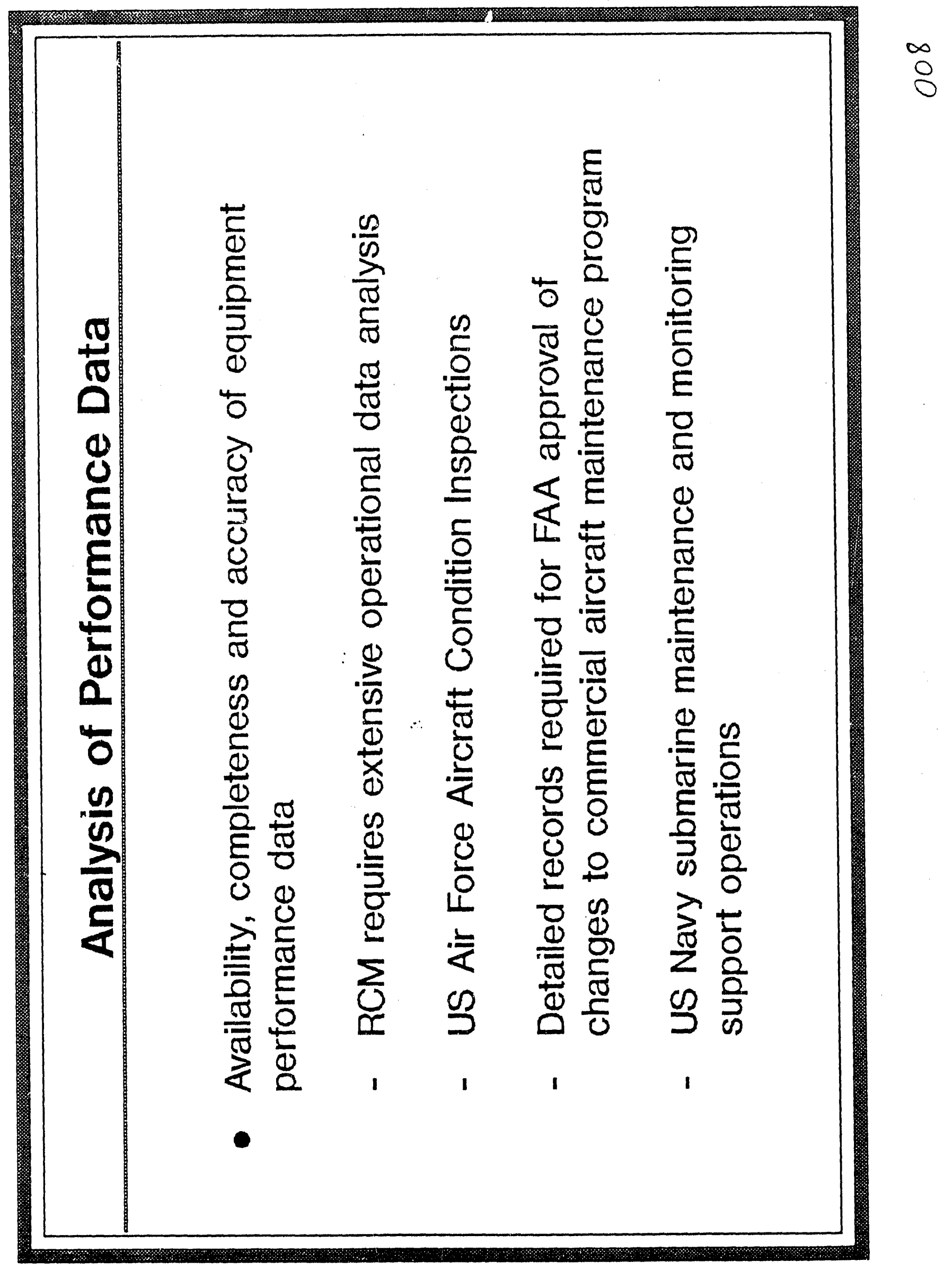




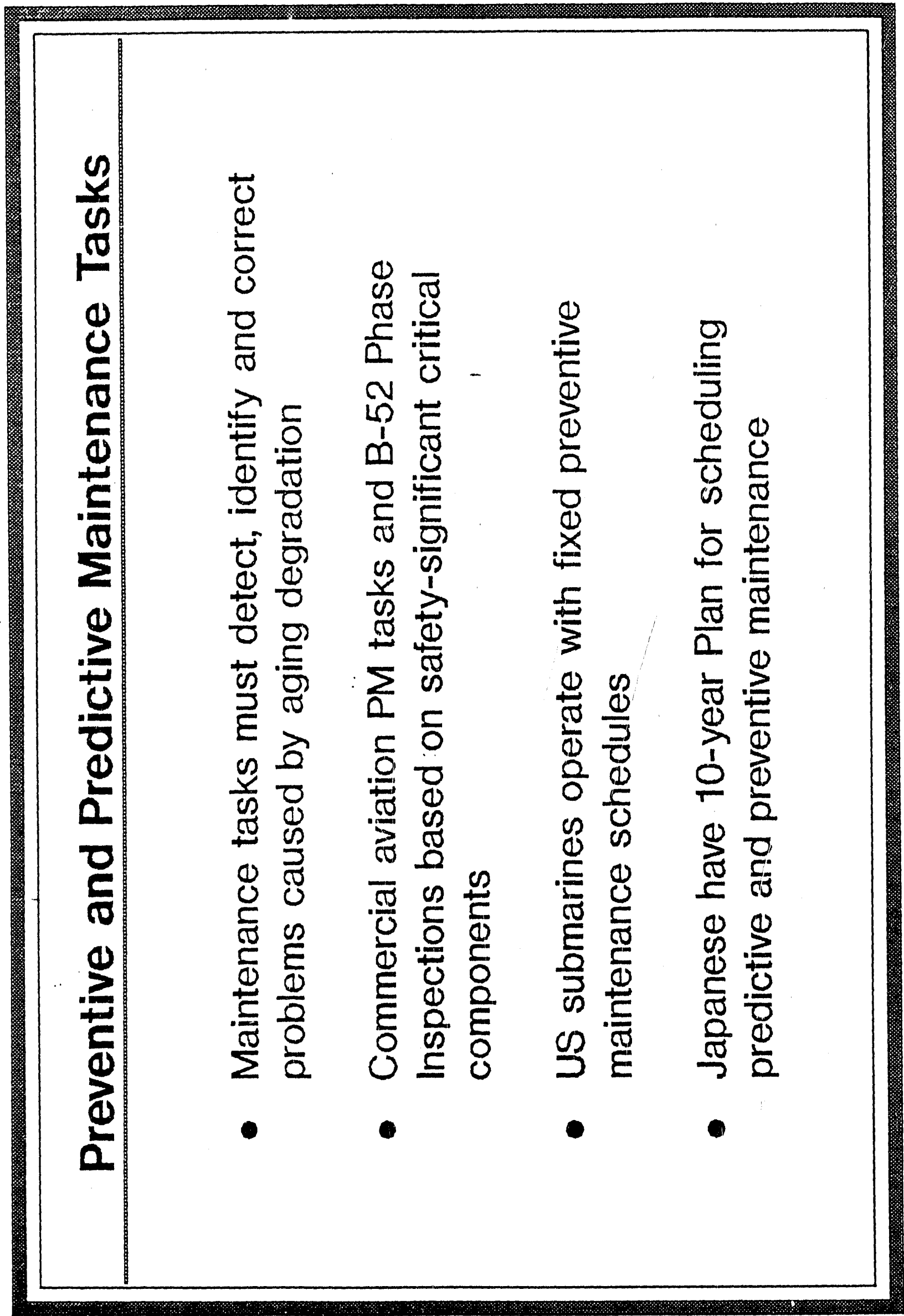




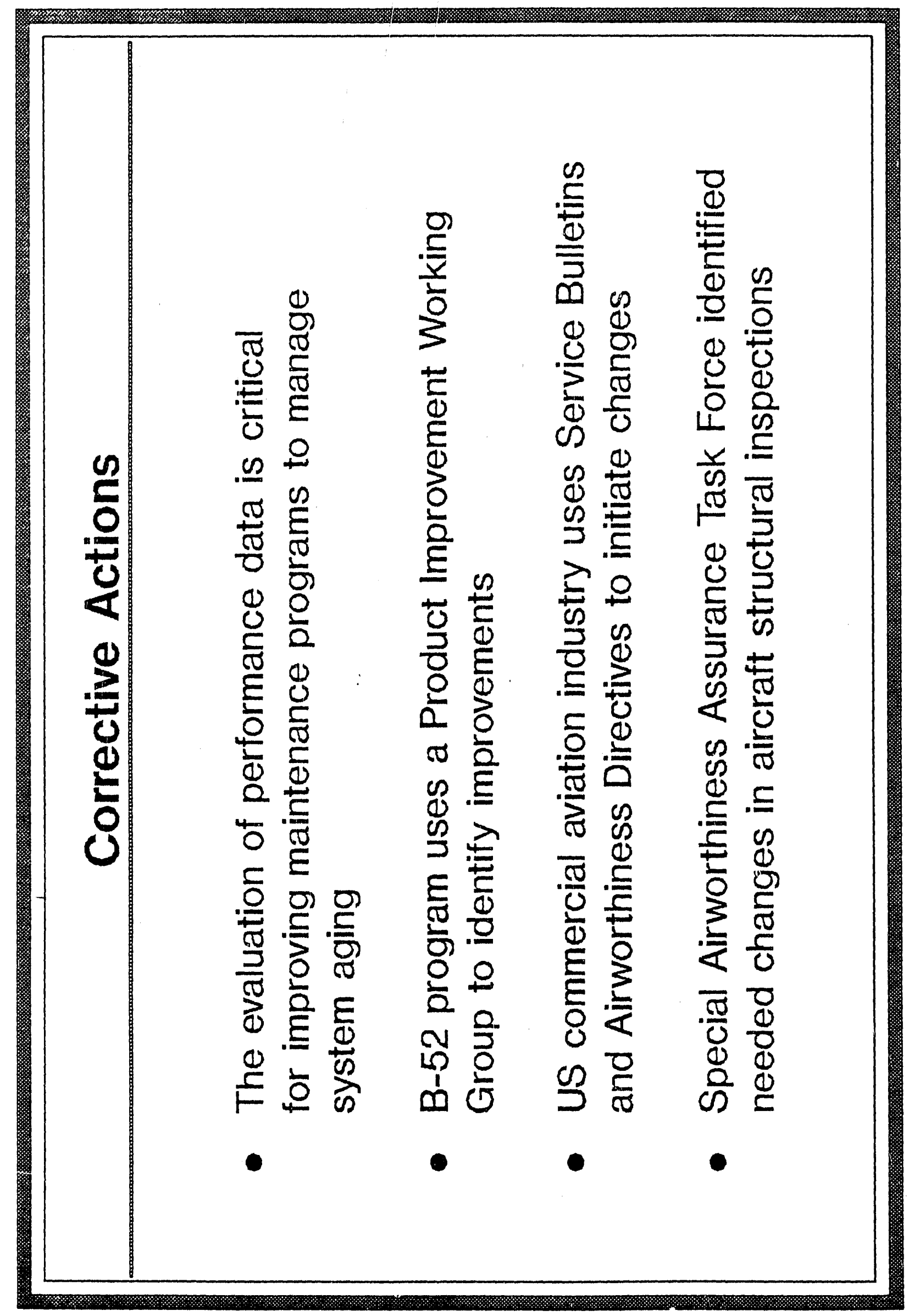

50 


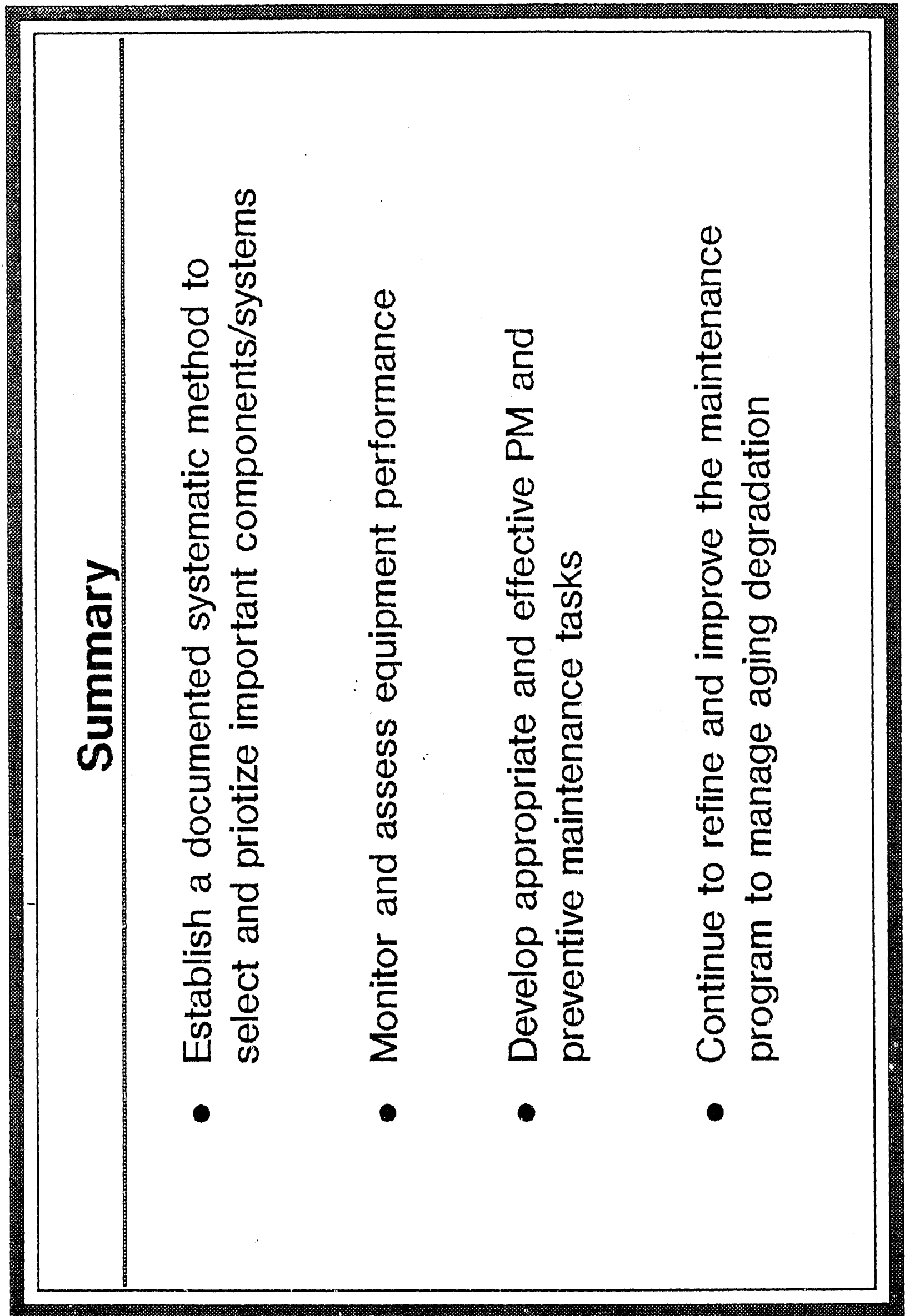

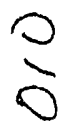



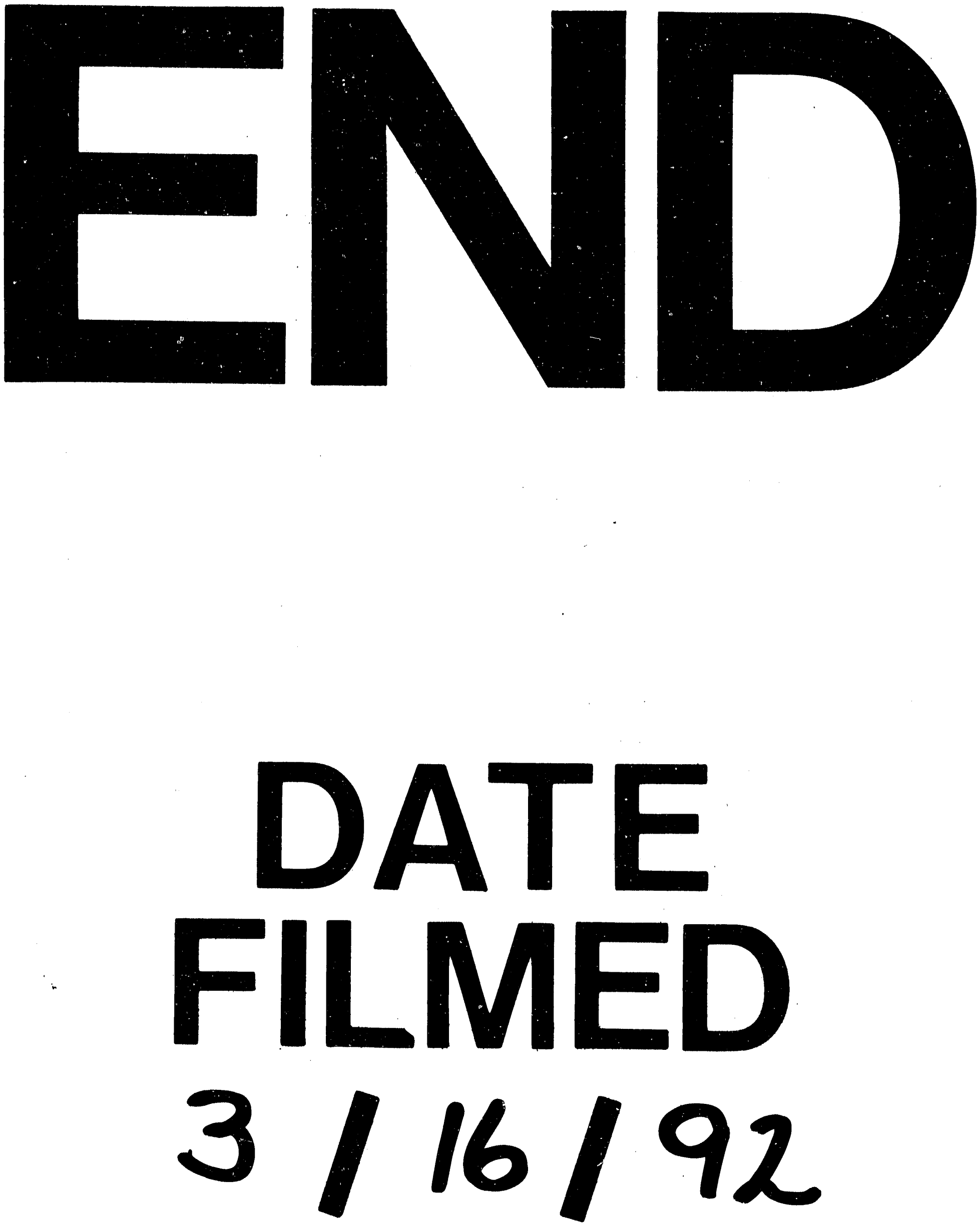
